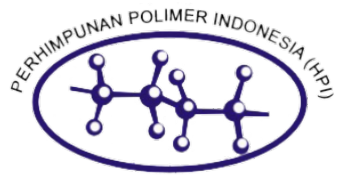

\title{
Produksi Gula Pereduksi dari Degradasi Pati Singkong melalui Proses Sonikasi disertai Pengadukan
}

\author{
Febriyati Puspasaria , Yoga Asmara ${ }^{a}$, Bramantyo Airlangga ${ }^{a}$, Prida Novarita Trisantia , Sumarno ${ }^{a}+$ \\ Pati singkong memiliki komposisi utama (dalam berat kering) 23\% amilosa dan $77 \%$ amilopektin yang tersusun atas \\ monomer glukosa. Oleh karena itu, pati dapat dikonversi menjadi gula pereduksi yang dimanfaatkan sebagai bahan baku \\ industri pangan maupun non pangan. Penelitian ini bertujuan untuk mempelajari pengaruh waktu proses sonikasi \\ terhadap konsentrasi gula pereduksi yang dihasilkan. Proses sonikasi dilakukan terhadap suspensi pati 1/20 (w/v) pada \\ kondisi operasi frekuensi $20 \mathrm{kHz}$, amplitudo $50 \%$ dan suhu $60^{\circ} \mathrm{C}$ untuk berbagai waktu proses (15-120 menit) disertai \\ pengadukan $250 \mathrm{rpm}$. Produk yang dihasilkan dari proses sonikasi dipisahkan antara solid dan liquid. Untuk produk solid \\ dianalisis dengan menggunakan Scanning Electron Microscopy (SEM) dan X-Ray Diffraction (XRD). Sedangkan produk \\ liquid dianalisis menggunakan Spektrofotometer UV-Vis dengan metode DNS. Berdasarkan hasil analisa DNS, dengan \\ semakin lamanya waktu proses diperoleh peningkatan konsentrasi gula pereduksi dan konsentrasi maksimum sebesar \\ $0,133 \mathrm{mg} \mathrm{mL}^{-1}$. Hasil foto SEM menunjukkan bahwa sebagian granula pati rusak (pecah), dan dari hasil analisa XRD \\ didapatkan penurunan derajat kristalinitas.
}

Received

10 October 2018

Received in revised form

Accepted

28 December 2018

Published

31 December 2018

DOI: $10.37889 / \mathrm{mpi} .2018 .21 .2 .3$
The main composition of cassava starch is (in dry weight) $23 \%$ amylose and $77 \%$ amylopectin, which is composed of glucose monomers. Therefore, starch can be converted to reducing sugar that is used as a raw material for food and nonfood industries. This study aims to study several sonication processes on the concentration of reducing sugars produced. The sonication process was carried out on $1 / 20$ (w/v) starch suspension at $20 \mathrm{kHz}$ operating frequency, $50 \%$ amplitude, and $60{ }^{\circ} \mathrm{C}$ temperature for various time processes (15-120 minutes) for stirring $250 \mathrm{rpm}$. Products produced from the sonication process between solid and liquid. For solid products analyzed using Scanning Electron Microscopy (SEM) and X-Ray Diffraction (XRD). While liquid products were analyzed using UV-Vis Spectrophotometer with DNS method. Based on the results of DNS analysis, the longer the process has obtained the increase in the concentration of reducing sugars and the maximum concentration of $0.133 \mathrm{mg} \mathrm{mL}^{-1}$. SEM image results showed that some starch granules were damaged (broken), and from the results of XRD analysis, it was found that the degree of crystallinity was decreased.

Kata kunci: Degradasi, gula pereduksi, pati singkong, pengadukan, sonikasi.

\section{Pendahuluan}

Pati (tepung tapioka) merupakan salah satu karbohidrat yang terdapat pada umbi tanaman singkong. ${ }^{1}$ Komposisi utama pati singkong terdiri dari $23 \%$ (dry wt) amilosa dan $77 \%$ (dry wt) amilopektin. ${ }^{2}$ Amilosa adalah polimer rantai lurus yang satuan glukosa anhidrousnya dihubungkan oleh ikatan $\alpha-1,4$ glikosidik yang strukturnya cenderung pada daerah amorf. Sedangkan amilopektin adalah polimer rantai bercabang yang menghubungkan ikatan $\alpha$ 1,4 glikosidik dengan $5 \%$ ikatan $\alpha-1,6$ glikosidik yang strukturnya cenderung pada daerah kristalin. Struktur molekul pada pati tersusun atas monomer glukosa, sehingga pati dapat dikonversi menjadi gula pereduksi melalui proses degradasi. Salah satu produk gula pereduksi ialah glukosa. Glukosa merupakan produk yang cukup potensial dan prospektif untuk dikembangkan karena dimanfaatkan sebagai bahan baku industri pangan maupun non pangan. ${ }^{1}$

\footnotetext{
a. Departemen Teknik Kimia, Institut Teknologi Sepuluh Nopember, Kampus ITS Sukolilo, Surabaya 60111, Indonesia

+ Corresponding author: onramus@chem-eng.its.ac.id.
}

Degradasi pati telah dilakukan oleh para peneliti sebelumnya menggunakan proses secara konvensional maupun non konvensional untuk memproduksi gula pereduksi. Secara konvensional dapat dilakukan dengan penggunaan asam dan enzim. ${ }^{3}$ Sedangkan secara non konvensional dilakukan dengan menggunakan microwave ${ }^{4}$ hidrotermal ${ }^{5}$ dan sonikasi. ${ }^{6}$

Sonikasi merupakan proses degradasi secara non konvensional menggunakan gelombang suara dengan frekuensi diatas $18 \mathrm{kHz}$ yang ditransferkan oleh probe melalui media cair, sehingga bersentuhan langsung dengan cairan. Degradasi dengan proses sonikasi akan memberikan efek perubahan struktur kimia maupun fisika pada pati. Proses sonikasi menghasilkan kavitasi akustik dalam cairan akibat fluktuasi tekanan dan kenaikan suhu yang menyebabkan tekanan uap dalam gelembung meingkat sehingga terjadi ledakan (collapse) yang menimbulkan microjetting. Tidak hanya memberikan efek fisik, namun proses sonikasi juga memberikan efek kimia yang disebabkan oleh hot spot local yang terjadi pada wilayah interfacial antara gelembung dan cairan yang berdekatan sehingga menimbulkan terjadinya radikal $\mathrm{OH}$ dan $\mathrm{H}$. Namun pada penelitian sebelumnya, proses sonikasi hanya menghasilkan konsentrasi gula pereduksi sebesar $18 \%{ }^{7}$ 
Dari uraian sebelumnya diketahui bahwa sonikasi merupakan metode degradasi pati yang dapat menghasilkan gula pereduksi. Namun kemampuannya dalam memproduksi gula pereduksi masih memiliki keterbatasan. Hal ini disebabkan bentuk struktur makromolekular pati yang tersusun dari struktur daerah kristalin (amilopektin) yang saling berikatan secara selang seling dengan struktur daerah amorf (amilosa) membentuk double helix yang kokoh. Struktur tersebut menghambat air ataupun reagen kimia untuk membuat kontak dengan seluruh bagian molekul pati. Maka dari itu dilakukan modifikasi pada proses sonikasi yang disertai pengadukan untuk lebih mengoptimalkan produksi gula pereduksi yang dihasilkan, mengefisiensikan waktu proses dan sebagai proses degradasi yang ramah lingkungan.

Penerapan pengadukan pada proses tersebut akan membantu melarutkan pati dalam air sehingga meningkatkan homogenisasi pada pati. Dengan larutnya pati dalam air, maka mempermudah reaksi pemotongan ikatan glikosidik terhadap rantai polimer pati yang dilakukan oleh proses sonikasi untuk memproduksi gula pereduksi lebih optimal. Oleh karena itu, tujuan dari penelitian ini ialah untuk mempelajari pengaruh waktu proses sonikasi terhadap konsentrasi gula pereduksi yang dihasilkan.

\section{Metode Percobaan}

\section{Alat dan Bahan}

Dalam penelitian ini menggunakan pati dari singkong segar di Kabupaten Mojokerto, Jawa Timur sebagai bahan baku. Pati tersebut dikeringkan dan diseragamkan ukurannya menjadi 40 mesh. Bahan baku lainnya yang digunakan ialah Aquadest diperoleh dari UD, Sumber IImiah Persada.

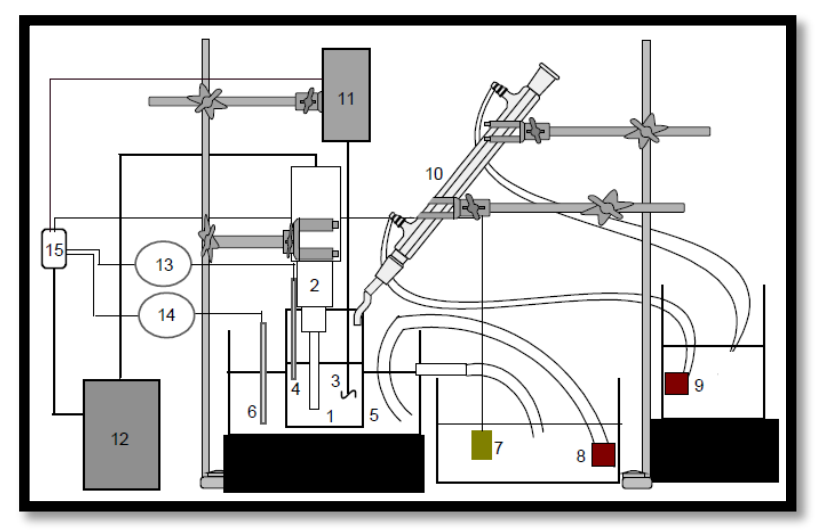

Gambar 1. Skema Proses Sonikasi disertai pengadukan.

\section{Keterangan :}
1. Reaktor sonikasi
2. Probe sonikasi
3. Pengaduk
4. Thermocouple reaktor
5. Waterbath
6. Thermocouple waterbath
7. Heater
8. Pompa

Untuk bahan analisa yang digunakan ialah D-glucose $99,9 \%$ diperoleh dari Merck, potassium sodium tartrate tetrahydrate diperoleh dari Merck, sodium hydroxide $(\mathrm{NaOH})$ diperoleh dari Merck, dan reagen 3,5-dinitrosalicylic acid (DNS) diperoleh dari Sigma-Aldrich.

Sistem proses sonikasi disertai pengadukan dapat dilihat pada Gambar 1. Alat ultrasonik yang digunakan ialah high-intensity ultrasonic processor (VCX 500, Sonics and Materials Inc, USA). Untuk alat yang digunakan pada analisa produk solid menggunakan Scanning Electron Microscopy (SEM; EVO MA 10, Carl Zeiss, Germany) untuk mengetahui perubahan struktur dan morfologi dari native pati sebelum dan setelah proses dan X-Ray Diffraction (XRD; Ex Malvern Panalytical, UK) untuk mengetahui perubahan derajat kristanilitas sebelum dan sesudah proses. Sedangkan alat yang digunakan untuk analisa produk liquid menggunakan Spektrofotometer UV-Vis (Shimadzu, Japan) dengan reagen 3,5-dinitrosalicylic acid untuk mengestimasi total kadar gula pereduksi yang dihasilkan hingga tahapan akhir proses.

\section{Cara Kerja}

Penelitian ini diawali dengan persiapan bahan baku dengan membuat suspensi pati singkong dalam aquadest dengan perbandingan $1 / 20(\mathrm{w} / \mathrm{v})$ dalam reaktor $400 \mathrm{~mL}$. Kemudian mengaduk suspensi pati singkong hingga homogen.

Untuk tahap proses sonikasi yang disertai pengadukan diawali dengan memasukkan suspensi yang telah dihomogenkan ke dalam reaktor. Kemudian memasukkan probe sonikasi ke dalam reaktor yang berisi suspensi pati. Kemudian melakukan proses sesuai dengan variabel yang telah ditentukan. Selanjutnya sampel produk yang dihasilkan dari proses dipisahkan antara solid dan liquid. Produk solid dianalisis dengan menggunakan Scanning Electron Microscopy (SEM) dan X-Ray Diffraction (XRD), sedangkan untuk produk liquid dianalisis dengan Spektrofotometer UV-Vis menggunakan reagen 3,5-dinitrosalicylic acid.

\section{Hasil dan Pembahasan}

Proses degradasi melibatkan molekul air untuk dapat merusak struktur pati, sehingga terjadi pemutusan ikatan glikosidik pada struktur pati. Proses sonikasi dilakukan terhadap suspensi pati $1 / 20$ $(\mathrm{w} / \mathrm{v})$ pada kondisi operasi frekuensi $20 \mathrm{kHz}$, amplitudo 50\%, dan suhu $60{ }^{\circ} \mathrm{C}$ untuk berbagai waktu proses (15-120 menit) disertai pengadukan $250 \mathrm{rpm}$. Produk yang dihasilkan dari proses sonikasi dipisahkan antara solid dan liquid. Untuk produk solid dianalisis dengan menggunakan SEM dan XRD. Sedangkan produk liquid dianalisis menggunakan Spektrofotometer UV-Vis menggunakan reagen 3,5-dinitrosalicylic acid (DNS).

Untuk produk padatan dianalisis dengan menggunakan SEM yang bertujuan untuk mengetahui perubahan struktur dan morfologi dari native pati sebelum maupun setelah proses sonikasi disertai pengadukan. 


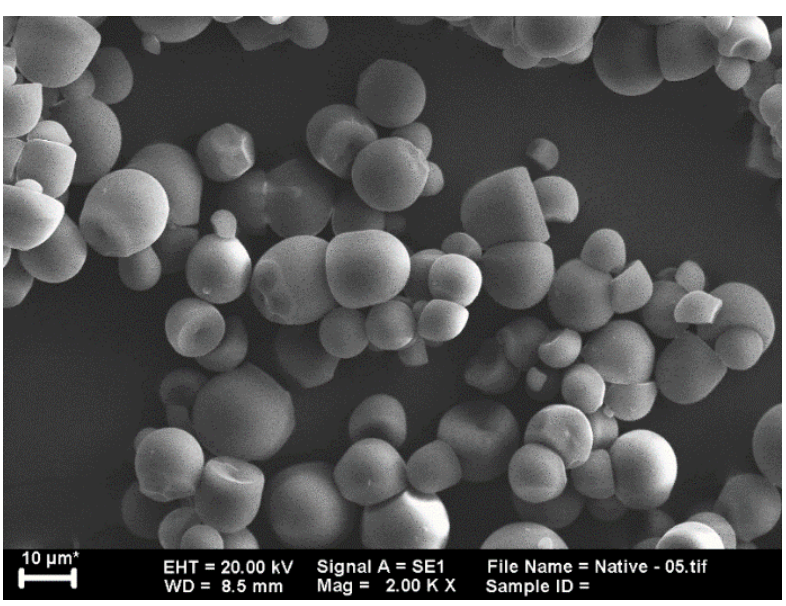

(a)

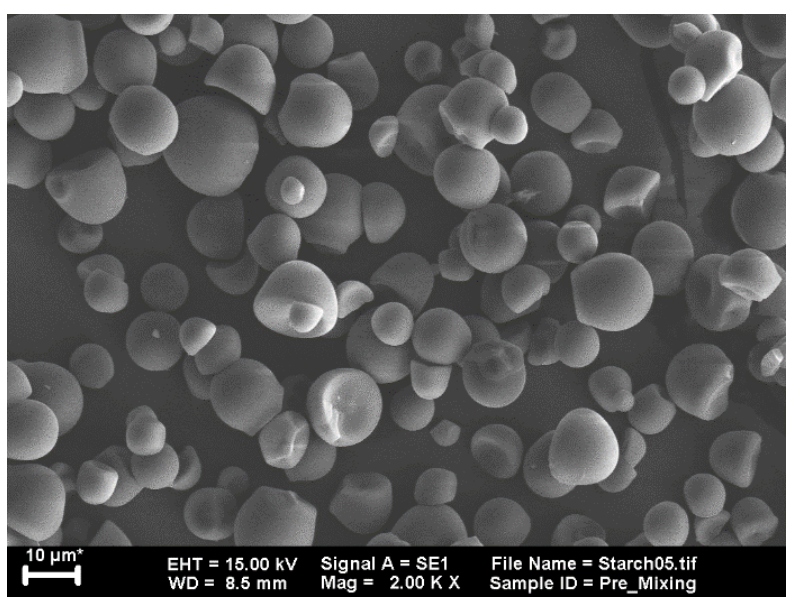

(b)

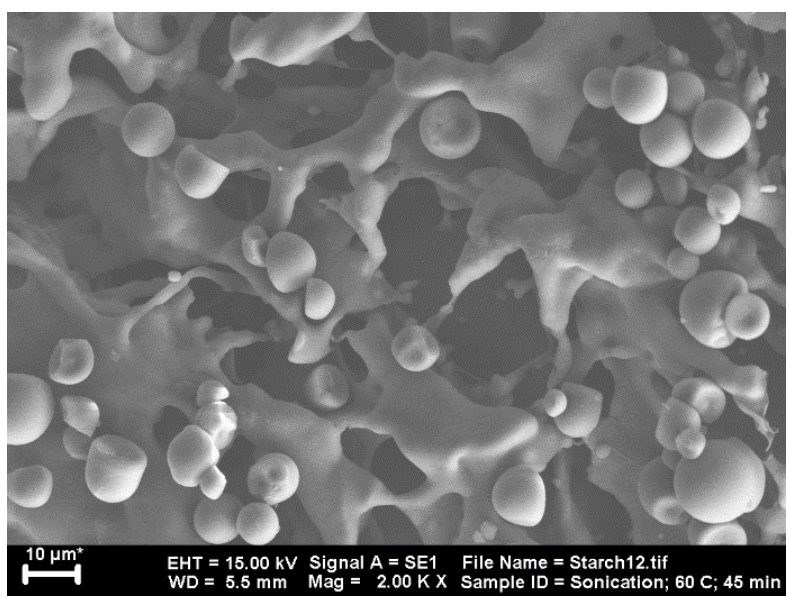

(c)

Gambar 2. Hasil analisa foto SEM dari pati dengan pembesaran 2000 kali selama 45 menit: (a) native pati; (b) pre-mixing selama 2 menit pada suhu ruang; (c) sonikasi disertai pengadukan pada suhu $60^{\circ} \mathrm{C}$ selama 45 menit.

Berdasarkan hasil analisa SEM dari native pati pada Gambar 2. menunjukkan bahwa struktur dari granula pati (a) awalnya cenderung berkelompok, berbentuk oval dengan bagian atas terpotong. Setelah pre-mixing 2 menit (b) bentuk dan ukuran dari granul pati masih sama seperti pada native, akan tetapi sebagian dari granula mulai merenggang antara satu dengan yang lain. Kemudian setelah dilakukannya proses sonikasi disertai pengadukan pada suhu $60^{\circ} \mathrm{C}$ (c) terlihat struktur granul pati sebagian rusak (pecah). Hal ini dipengaruhi oleh gelombang ultrasonik yang mengenai pati. Pati yang terkena gelombang ultrasonik mengakibatkan terbentuknya kavitasi. Pada saat kavitasi terjadi siklus pembentukan, pertumbuhan, dan keruntuhan gelembung. Tekanan uap yang lebih tinggi dapat mendorong ke arah pembentukan gelembung yang lebih mudah sehingga menyebabkan terjadi ledakan kavitasi. Ledakan kavitasi ini menghasilkan radikal hidroksil $\left({ }^{\circ} \mathrm{OH}\right)$ dan radikal hidrogen $\left({ }^{\circ} \mathrm{H}\right)$ yang semakin banyak untuk kemudian menyerang ikatan glikosidik pada pati.

Produk padatan dianalisis dengan menggunakan X-Ray Diffraction (XRD) yang bertujuan untuk mengetahui perubahan kristanilitas dari pati setelah proses sonikasi yang disertai dengan pengadukan.

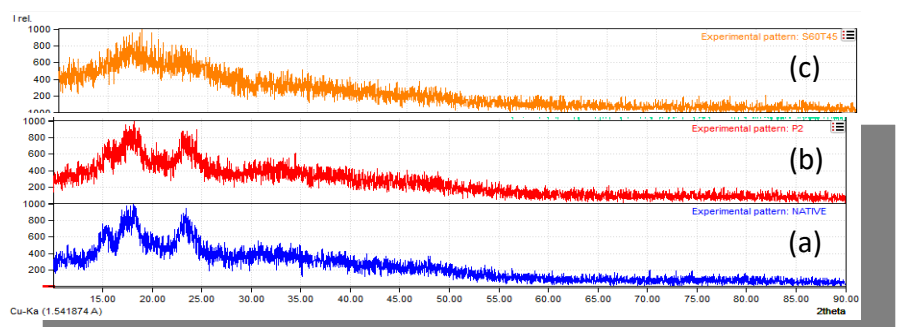

Gambar 3. Hasil analisa XRD dari pati: (a) native pati; (b) pre-mixing selama 2 menit pada suhu ruang; (c) sonikasi disertai pengadukan pada suhu $60^{\circ} \mathrm{C}$.

Terlihat pada Gambar 3, (a) native pati memiliki kristalinitas sebesar $35,62 \%$ dengan terdapatnya 4 puncak pada $2 \theta=15,3864^{\circ}$; $18,1972^{\circ}$ dan $23,2710^{\circ}$. Setelah proses pre-mixing selama 2 menit (b), pati memiliki kristalinitas sebesar $33,82 \%$ dengan puncak $2 \theta=$ $15,2904^{\circ}$. Kemudian setelah dilakukan proses sonikasi disertai dengan pengadukan pada suhu $60^{\circ} \mathrm{C}$ sebesar $10,77 \%$ dengan sudah tidak terdapatnya puncak lagi (c). Dari tahapan-tahapan tersebut menunjukkan bahwa terjadinya perubahan kristalinitas dengan menurunnya intensitas seperti yang dijelaskan sebelumnya. Hal ini disebabkan karena pada proses sonikasi dapat merenggangkan struktur molekul kristalin dan membuatnya tampak seperti amorf sehingga menyisakan molekul kristalin. Hal ini yang disebabkan karena adanya efek fisik maupun kimia yang dihasilkan oleh proses sonikasi sehingga merubahnya menjadi struktur amorf dan menurunkan intensitas kristalinitasnya.

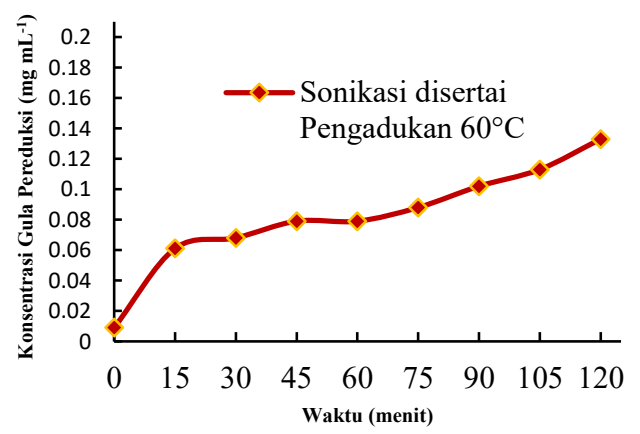

Gambar 4. Hasil analisa gula pereduksi proses sonikasi disertai pengadukan untuk berbagai waktu pada suhu $60^{\circ} \mathrm{C}$. 
Selanjutnya juga dilakukan analisa pada produk liquidnya dengan metode DNS untuk mengestimasi total gula pereduksi yang dihasilkan. Berdasarkan hasil analisa menunjukkan bahwa dengan semakin lamanya waktu proses maka terjadi peningkatan konsentrasi gula pereduksi. Dan dari hasil tersebut didapatkan konsentrasi maksimum sebesar $0,133 \mathrm{mg} \mathrm{mL}^{-1}$. Hal ini disebabkan karena semakin lamanya waktu proses maka semakin banyak pula microbubble yang dihasilkan yang menyebabkan banyaknya radikal $\mathrm{OH}$ yang menyerang ikatan glikosidik sehingga menjadikan ikatan glikosidik semakin mudah terpotong.

\section{Kesimpulan}

Berdasarkan hasil analisa DNS, dengan semakin lamanya waktu proses maka diperoleh peningkatan konsentrasi gula pereduksi dan konsentrasi maksimum sebesar $0,133 \mathrm{mg} \mathrm{mL}^{-1}$. Hasil foto SEM menunjukkan bahwa sebagian granula pati rusak (pecah), dan dari hasil analisa XRD didapatkan penurunan derajat kristalinitas.

\section{Ucapan Terima Kasih}

Penulis mengucapkan terima kasih kepada Laboratorium Teknologi Material, Departemen Teknik Kimia, Institut Teknologi Sepuluh Nopember yang telah memberi dukungan sehingga terlaksananya penelitian ini.

\section{Referensi}

1 J. BeMiller dan R. Whistler, Starch: Chemistry and technology, 2009, 53(9).

2 R.A. Freitas, R.C. Paula, J.P.A. Feitosa, S. Rocha dan M.R. Sierakowski, Amylose contents, rheological properties and gelatinization kinetics of yam (Dioscorea alata) and cassava (Manihot utilissima) starches, Carbohydr. Polym., 2004, 55(1), 3-8.

3 A. Ayoola, O. Adeeyo, V. Efeovbokhan dan D.A. Olasimbo, Optimum Hydrolysis Conditions of Cassava Starch for Glucose Production, Int. J. Adv. Res. IT Eng., 2013, 2(1), 93-101.

4 E. Hermiati et al., Improvement of microwave-assisted hydrolysis of cassava pulp and tapioca flour by addition of activated carbon, Carbohydr. Polym., 2012, 87(1), 939-942.

5 F. Puspasari, Y. Asmara dan P.N. Trisanti, Produksi Gula Pereduksi dari Depolimerisasi Pati Singkong Melalui Proses Pelarutan disertai Pemanasan dan Hidrotermal, Seminar Nasional Teknik Kimia Kejuangan, 2017, April, 1-6.

6 A. Hernoux, J.M. Lévêque, U. Lassi, S. Molina-Boisseau dan M.F. Marais, Conversion of a non-water soluble potato starch waste into reducing sugars under non-conventional technologies, Carbohydr. Polym., 2013, 92(2), 2065-2074.

7 A. Hernoux-villie et al., Simultaneous Microwave/UltrasoundAssisted Hydrolysis of Starch-Based Industrial Waste into Reducing Sugars, 2013. 